\title{
OPEN Response of the chemical structure of soil organic carbon to modes of maize straw return
}

\author{
Shuqing Zheng ${ }^{1,5}$, Jiuming Zhang ${ }^{2,3,5}$, Fengqin $\mathrm{Chi}^{2}$, Baoku Zhou ${ }^{2}$, Dan Wei ${ }^{4 凶}$, Enjun Kuang ${ }^{2}$, \\ Yu Jiang ${ }^{1}$, Gang $\mathrm{Mi}^{1}$ \& Yu ping Chen ${ }^{1}$
}

Elucidating the chemical structure of soil organic matter (SOM) is important for accurately evaluating the stability and function of SOM. Aboveground vegetation directly affects the quantity and quality of exogenous organic matter input into the soil through plant residues and root exudates, which in turn affects soil microbial species, community structure, and activity, and ultimately impacts the chemical structure of SOM. In this study, a ${ }^{13} \mathrm{C}$ nuclear magnetic resonance technique was used to analyze the chemical structure characteristics of soil organic carbon $(\mathrm{SOC})$ under various rates of straw returning combined with rotary tillage and under full straw mulching. The results showed that full straw returning with rotary tillage and full straw mulching more effectively increased the SOC content than reduced rate of straw returning (1/2 and $1 / 3$ of full straw) with rotary tillage. The contents of alkyl $C$ and alkoxy $\mathrm{C}$ in the functional groups of SOC under various straw returning treatments were increased compared with those under the treatment of maize stubble remaining in soil (CK). Furthermore, the contents of aromatic $\mathrm{C}$ and carboxyl $\mathrm{C}$ were decreased, which were consistent with the chemical shift changes of SOC. Compared with CK treatment, straw returning decreased the content of aromatic $\mathrm{C}$ in the functional groups of SOC, but increased the content of alkoxy $\mathrm{C}$, which could be associated with the change in integral areas of absorption peaks of alkyl $C$ and alkoxy $C$ moving toward left and right, respectively. The content of total SOC was significantly positively $(P<0.05)$ correlated with that of alkoxy $C$ and significantly negatively $(P<0.01)$ correlated with that of aromatic $C$. The molecular structure of $S O C$ tends to be simplified due to the decreasing in refractory $C$ and the increasing in easily decomposed $\mathrm{C}$ after straw returning to the field.

Elucidating the chemical structure and stability of soil organic matter (SOM) is key to understanding soil fertility and carbon (C) cycling. ${ }^{13} \mathrm{C}$ nuclear magnetic resonance $\left({ }^{13} \mathrm{C}-\mathrm{NMR}\right)$ spectroscopy is an advanced technology for determining the chemical structure of SOM. It can simultaneously perform qualitative and quantitative analysis for the chemical composition of SOM and is thus an effective means of studying the chemical structure and transformation of SOM ${ }^{1}$. Differences in the composition of plant residues reflect the differences in SOM under continuous degradation of residues, which is the primary factor accounting for the variation in the chemical structure of soil organic carbon (SOC) under different land use types ${ }^{2}$. The chemical structure and stability of SOC are closely related to the types of aboveground vegetation and the quantity and quality (chemical structure) of exogenous organic matter entering soil. Clemente et al. ${ }^{3}$ found that the chemical structure of SOC was changed with the decomposition of the addition materials from different parts of maize plant (roots, stems, and leaves) to soil. A high carbohydrate content is found in SOC under the addition of maize stem, and a high aliphatic $\mathrm{C}$ content is recorded in the soil humus under the addition of maize leaf. Maize leaf tissue has a high aliphatic C content, which contributes to the stability of SOC. Increasing the input of exogenous organic matter is an important measure for maintaining and enhancing SOC and improving soil structure.

Straw returning to the soil not only has the potential to alleviate soil degradation, but also increases the sequestration potential of SOC. Therefore, studying the effects of continuous maize straw returning and tillage

\footnotetext{
${ }^{1}$ Heihe Branch Academy of Heilongjiang Academy of Agricultural Sciences, Heihe 164300, China. ${ }^{2}$ Key Laboratory of Soil Environment and Plant Nutrition of Harbin, Institute of Soil and Fertilizer and Environment Resources, Heilongjiang Academy of Agricultural Sciences, Harbin 150086, China. ${ }^{3}$ Heilongjiang Academy of Agricultural Sciences Postdoctoral Program, Institute of Soil and Fertilizer and Environment Resources, Heilongjiang Academy of Agricultural Sciences, Harbin 150086, China. ${ }^{4}$ Institute of Plant Nutrition and Resources, Beijing Academy of Agriculture and Forestry Sciences, Beijing 100097, China. ${ }^{5}$ These authors contributed equally: Shuqing Zheng and Jiuming Zhang. ${ }^{\circledR}$ email:wd2087@163.com
} 


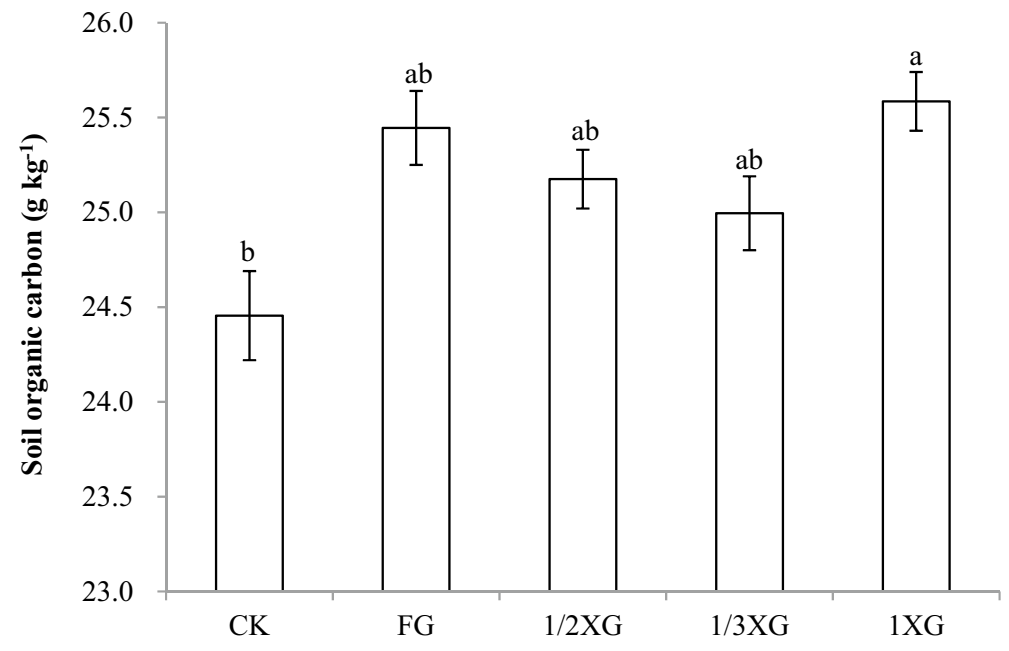

Figure 1. Effect of straw returning on soil organic carbon content. $C K$ control (stubble remaining in soil), $F G$ full straw mulching, $1 X G$ full straw returning combined with rotary tillage, $1 / 2 X G 1 / 2$ of full straw returning combined with rotary tillage, $1 / 3 \times G 1 / 3$ of full straw returning combined with rotary tillage.

modes as well as the amount of returning straw on the chemical structure of SOC is significant for reducing soil degradation and improving soil quality.

\section{Results}

Changes in soil organic carbon content under different straw returning measures. It can be seen from Fig. 1 that the highest content of SOC $\left(25.6 \mathrm{~g} \mathrm{~kg}^{-1}\right)$ was found in the treatment of full straw returning combined with rotatory tillage (1XG), and the lowest content of SOC $\left(24.5 \mathrm{~g} \mathrm{~kg}^{-1}\right)$ was found in the treatment of stubble remaining in soil (CK). The difference in SOC was significant $(P<0.05)$ between these treatments. The SOC content in the full straw mulching treatment was $25.4 \mathrm{~g} \mathrm{~kg}^{-1}$, which was higher than that in the CK treatment and in the treatments of reduced rate of straw returning combined with rotary tillage ( $1 / 2$ XG and $1 / 3$ $\mathrm{XG})$, but this difference was not statistically significant $(P>0.05)$. The above results showed that long-term straw return could impact the soil organic carbon content. Of the treatments, full rotary tillage return performed better than reduced-rate rotary tillage return and straw mulching return.

CPMAS ${ }^{13}$ C-NMR spectral characteristics of soil organic carbon with different straw returning measures. As shown in Fig. 2, the absorption peak of alkyl C in SOC in the different straw returning treatments was around $24 \mathrm{ppm}$, which represented the chemical shift of the methyl $\mathrm{C}\left(\mathrm{CH}_{3}\right)$ in long-chain aliphatic compounds, wax, and cutin. The absorption peaks of alkoxy $\mathrm{C}$ were mainly around $66 \mathrm{ppm}$ and $97 \mathrm{ppm}$, which were assigned to the alkyl $\mathrm{C}$ of carbohydrate alcohols, amino sugars, and the di-O-alkyl $\mathrm{C}$ of hemicellulose, respectively. The absorption peak of aromatic $C$ was mainly around $122-125 \mathrm{ppm}$, mainly corresponding to the phenyl ring C (Aryl C) of tannin and lignin. In the carbonyl C region, the main signal appeared near $168 \mathrm{ppm}$, which was the absorption of carboxylic acid, ester, and amide $\mathrm{C}^{4}$.

In the alkyl $\mathrm{C}$ region, the chemical shifts of the absorption peaks of SOC functional groups were increased in all straw returning treatments compared with those in the CK treatment. The chemical shift of the absorption peaks in the $1 / 3 \mathrm{XG}$ treatment was $25.12 \mathrm{ppm}$, which was higher than that in the FG treatment, whereas the chemical shifts of the absorption peaks in $1 / 2 \mathrm{XG}$ and $1 \mathrm{XG}$ treatments were lower than that in the FG treatment. In the alkoxy $\mathrm{C}$ region, the chemical shifts of the absorption peaks of SOC functional groups in all straw returning treatments were increased compared with those in the CK treatment, and the chemical shifts in all straw returning combined with rotary tillage treatments were lower than that in the FG treatment. In the aromatic $\mathrm{C}$ region, the chemical shifts of the absorption peaks in all straw returning combined with rotary tillage treatments were lower than that in the CK treatment, and the smallest chemical shift of the absorption peak (123.13 ppm) was found in the $1 \mathrm{XG}$ treatment. In the carboxyl $\mathrm{C}$ region, the chemical shift of the absorption peak in straw returning combined with rotary tillage treatments $(1 / 3 \mathrm{XG}, 1 / 2 \mathrm{XG}$, and $1 \mathrm{XG})$ was lower than that in the $\mathrm{CK}$ treatment; and similarly, the lowest chemical shift of the absorption peak (167.57 ppm) was found in the full straw returning combined with rotary tillage treatment (Fig. $2 \mathrm{~b}-\mathrm{d}$ ). Compared with FG treatment, all straw returning combined with rotary tillage treatments increased the chemical shifts of the absorption peak of the alkyl C, and decreased those of alkoxy $\mathrm{C}$, aromatic $\mathrm{C}$, and carboxyl C of SOC.

Changes in the chemical structure of soil organic carbon under different straw returning measures. Compared with that of $\mathrm{CK}$, all straw returning combined with rotary tillage treatments increased the contents of alkyl C and alkoxy $\mathrm{C}$ in the SOC functional groups, but decreased the contents of aromatic $\mathrm{C}$ and carboxyl C (Table 1). The highest content of alkyl C (25.2\%) was found in the $1 / 2 \mathrm{XG}$ treatment. The alkoxy C contents in the $1 / 2$ XG and 1 XG treatments were $2.6 \%$ higher significantly $(P<0.05)$ than that in the CK treat- 

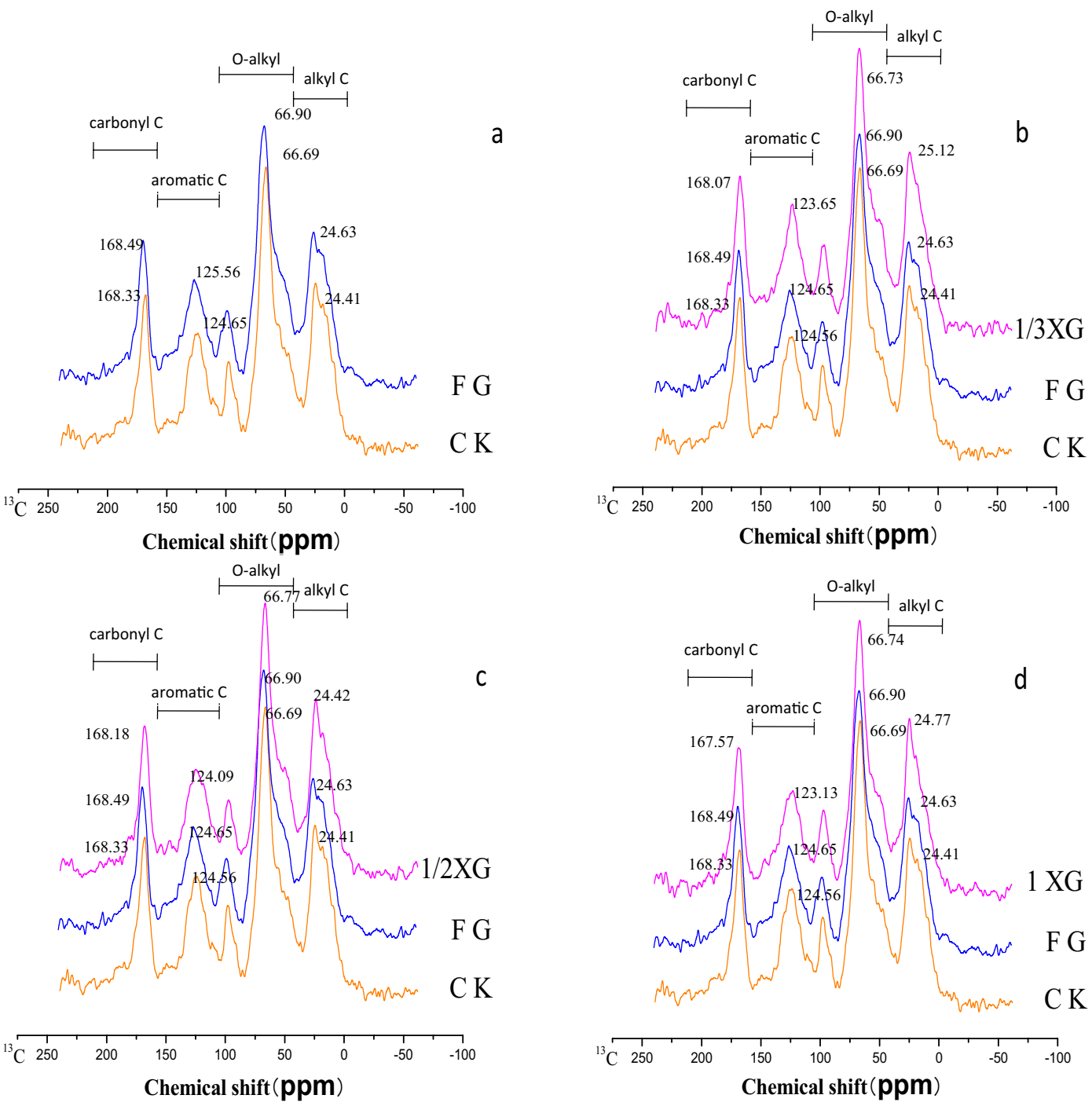

Figure 2. CPMAS ${ }^{13} \mathrm{C}-\mathrm{NMR}$ spectra of organic carbon in Black soil treated with different straw returning treatments. $C K$ control (stubble remaining in soil), $F G$ full straw mulching, $1 X G$ full straw returning combined with rotary tillage, $1 / 2 X G 1 / 2$ of full straw returning combined with rotary tillage, $1 / 3 X G 1 / 3$ of full straw returning combined with rotary tillage. (a) The comparison of FG with CK; (b) the comparison among 1/3 XG, FG, and CK; (c) is the comparison among 1/2 XG, FG, and CK; (d) is the comparison among XG, FG, and CK.

\begin{tabular}{|l|l|l|l|l|l|l|l|}
\hline & & & & & & & \\
Treatment & Alkyl C (\%) & O-alkyl C (\%) & Aromatic C (\%) & Carbonyl C (\%) & $\begin{array}{l}\text { Hydrophobic C/ } \\
\text { Aromatic C }\end{array}$ & $\begin{array}{l}\text { Alkyl C/O- } \\
\text { alkyl C }\end{array}$ & $\begin{array}{l}\text { C/Hydrophilic } \\
\text { C }\end{array}$ \\
\hline CK & $24.2 \pm 0.12 \mathrm{a}$ & $38.3 \pm 0.39 \mathrm{~b}$ & $19.8 \pm 0.45 \mathrm{a}$ & $17.8 \pm 0.42 \mathrm{a}$ & $3.16 \pm 0.02 \mathrm{~b}$ & $0.63 \pm 0.03 \mathrm{a}$ & $0.78 \pm 0.02 \mathrm{a}$ \\
\hline FG & $24.9 \pm 0.19 \mathrm{a}$ & $39.1 \pm 0.36 \mathrm{ab}$ & $18.7 \pm 0.72 \mathrm{~b}$ & $17.4 \pm 0.56 \mathrm{a}$ & $3.43 \pm 0.03 \mathrm{a}$ & $0.64 \pm 0.03 \mathrm{a}$ & $0.77 \pm 0.03 \mathrm{a}$ \\
\hline $1 / 3 \mathrm{XG}$ & $24.8 \pm 0.11 \mathrm{a}$ & $38.9 \pm 0.55 \mathrm{~b}$ & $19.5 \pm 0.63 \mathrm{ab}$ & $16.8 \pm 0.38 \mathrm{~b}$ & $3.26 \pm 0.01 \mathrm{a}$ & $0.64 \pm 0.05 \mathrm{a}$ & $0.79 \pm 0.02 \mathrm{a}$ \\
\hline $1 / 2 \mathrm{XG}$ & $25.2 \pm 0.10 \mathrm{a}$ & $39.3 \pm 0.42 \mathrm{a}$ & $19.1 \pm 0.40 \mathrm{ab}$ & $16.4 \pm 0.34 \mathrm{~b}$ & $3.37 \pm 0.02 \mathrm{a}$ & $0.64 \pm 0.06 \mathrm{a}$ & $0.80 \pm 0.04 \mathrm{a}$ \\
\hline 1 XG & $24.7 \pm 0.10 \mathrm{a}$ & $39.3 \pm 0.43 \mathrm{a}$ & $18.5 \pm 0.31 \mathrm{~b}$ & $17.5 \pm 0.30 \mathrm{a}$ & $3.45 \pm 0.02 \mathrm{a}$ & $0.63 \pm 0.03 \mathrm{a}$ & $0.76 \pm 0.03 \mathrm{a}$ \\
\hline
\end{tabular}

Table 1. Relative proportions of functional groups with different chemical shift intervals in the CPMAS ${ }^{13} \mathrm{C}$ NMR spectra of black soil organic carbons from different straw return treatments. Aliphatic C/Aromatic $C$ (Alkyl C + O-alkyl C)/Aromatic C, Hydrophobic C/Hydrophilic C (Alkyl C + Aromatic C)/(O-alkyl C + Carbonyl C), $C K$ control (i.e., stubble remaining), $F G$ full straw mulching return, $1 X G$ full rotary tillage return, $1 / 2$ $X G 1 / 2$ rotary tillage return, $1 / 3 X G 1 / 3$ rotary tillage return. Different letters in the same column represent significant difference $(p<0.05)$. 

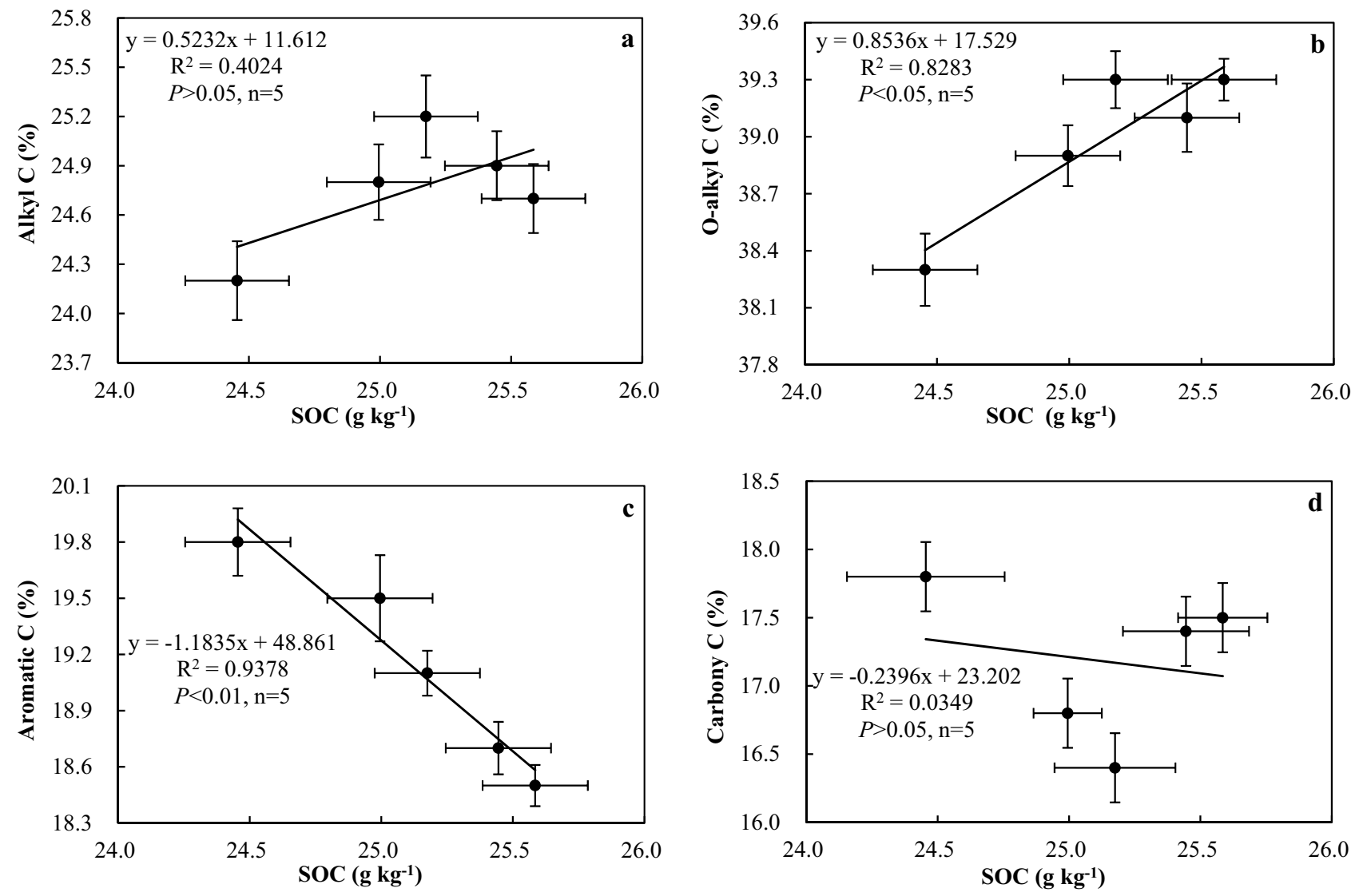

Figure 3. Correlation between soil organic carbon content, clay content, and relative proportion of organic carbon functional groups.

ments. The higher contents of aliphatic $\mathrm{C}$ (alkyl C+alkoxy $\mathrm{C}$ ) of SOC was found in the $1 / 2 \mathrm{XG}$ and in the $1 \mathrm{XG}$ treatments compared with $\mathrm{CK}$ treatment. The FG treatment and $1 \mathrm{XG}$ treatment exhibited a relatively large $(P<0.05)$ decrease in the content of aromatic $C$ than $C K$ treatment. The $1 / 2 \mathrm{XG}$ and $1 / 3 \mathrm{XG}$ treatments showed a relatively large $(P<0.05)$ decrease in the carboxyl $\mathrm{C}$ content than $\mathrm{CK}$.

The ratio of aliphatic $\mathrm{C}$ content to aromatic $\mathrm{C}$ content (aliphatic $\mathrm{C} /$ aromatic $\mathrm{C}$ ) was higher in the straw returning treatments than that in the $\mathrm{CK}$ treatment. The ratios of alkyl $\mathrm{C}$ content to alkoxy $\mathrm{C}$ content and hydrophobic $\mathrm{C}$ content to hydrophilic $\mathrm{C}$ content were not significantly different among each treatment.

Relationship between soil organic carbon and the chemical structure of soil organic carbon. The total SOC had a positive correlation with the contents of alkyl $\mathrm{C}$ and alkoxy $\mathrm{C}$ and a negative correlation with the contents of aromatic $\mathrm{C}$ and carboxyl $\mathrm{C}$ (Fig. 3). The total SOC content was significantly positively $(P<0.05)$ correlated with the content of alkoxy $\mathrm{C}$ and was significantly negatively $(P<0.01)$ correlated with the content of aromatic C (Fig. 3b,c). The increase in SOC content was more favorable for decreasing the aromatic $\mathrm{C}$ content and increasing the alkoxy $\mathrm{C}$ content.

\section{Discussion}

Straw returning improves soil structure and increase soil nutrients, while the mode and amount of straw returning to the field could inevitably affect soil structure and nutrient status. In this study, full straw returning combined with rotary tillage and full straw mulching more effectively increased the SOC content.

Compared with CK, each straw returning treatment increased the contents of alkyl C and alkoxy C of SOC functional groups and decreased the contents of aromatic $\mathrm{C}$ and carboxyl $\mathrm{C}$, which was consistent with the chemical shift changes of the absorption peaks of SOC functional groups in each straw returning treatment. The abundance peaks of alkyl $\mathrm{C}$ and alkoxy $\mathrm{C}$ moved toward left and right in straw returning treatment, respectively, which leads to the change in integral area of their abundance peaks. The alkyl C content of the soil organic carbon in each straw return treatment increased compared with that in the CK treatment, but the difference between the treatments was not significant. At the same time, the content of alkoxy $\mathrm{C}$ increased significantly, and the full rotary tillage return treatment exhibited the most significant drop in aromatic $\mathrm{C}$ content compared with that in CK $(P<0.05)$. The results indicated that the content of soil refractory carbon decreased following straw return, and the content of the carbon that is easily metabolized and utilized by microorganisms increased, with the 
result that the full rotary tillage return treatment was better than the full straw mulching return treatment. Straw addition to soil provides $\mathrm{C}$ and $\mathrm{N}$ sources for microorganism. About $8-35 \%$ of straw $\mathrm{C}$ can be preserved in soil as organic matter ${ }^{5}$. Microorganisms play important roles in soil $\mathrm{C}$ cycling, in turn, their metabolic products are the main components of SOC ${ }^{6}$. Lehmann et al. suggested that the stable SOC partly originates from microbial re-synthese or biomass re-cycling ${ }^{7}$. Further research should be combined microbial stabilized mechanism of SOC with chemical structure of SOC. The ratio of aliphatic $\mathrm{C}$ /aromatic $\mathrm{C}$ can reflect the complexity of the molecular structure of humic substances. A higher ratio indicates a lower content of aromatic core structures in humic substances, more aliphatic side chains, a lower degree of condensation, and a simpler molecular structure ${ }^{8}$. The results of this study demonstrated that the ratio of aliphatic $\mathrm{C} /$ aromatic $\mathrm{C}$ of the soil organic carbon in the full rotary tillage return treatment was higher than in the other treatments. The above results also further confirmed that with the continuous degradation of the residues, the differences in the composition of plant residues were ultimately converted into differences in the structure and composition of the soil organic matter ${ }^{2}$.

Most organic matter in the soil is important for the dynamics of soil organic matter. Alkyl C in SOC functional groups mainly originates from carbohydrate easily decomposed by soil microorganism, including hemicellulose, cellulose, polymeric and non-polymeric carbohydrates, and ethanol-like substance ${ }^{9}$. It means that alkyl C is belonged to labile organic C. Ratio of alkyl C to alkoxy $\mathrm{C}$ is a sensitive index for SOC decomposition degree, and can be used to evaluate the degree of alkylation of humic substance ${ }^{10}$. The lower ratio of alkyl C to alkoxy C indicates lower decomposed degree of soil organic matter. Hydrophobic alkyl-C plays an essential basic role in the accumulation and sequestration of SOC in forest and cultivated soils ${ }^{11}$. Aromatic $\mathrm{C}$ is mainly derived from organic compound with benzene ring, such as lignin, suberin, polypeptide and black $\mathrm{C}$, or is originated from microbial metabolites or charred organic matter, suggesting that aromatic $\mathrm{C}$ is belonged to recalcitrant organic $\mathrm{C}^{12}$. Mathers and $\mathrm{Xu}$ found that alkoxyl $\mathrm{C}$ is the easily decomposed functional group in plant residue ${ }^{13}$. During the initial decomposed period of plant residues, alkoxy $\mathrm{C}$ in them is rapidly decomposed and, on the contrary, aromatic and alkyl C is selectively stabilized in soil. Mahieu et al. ${ }^{14}$ showed that the soil with a higher organic matter content has a higher ratio of alkoxy C. The large amount of straw addition to soil could promote their decomposition in soil, which could lead to the instability of soil organic matter, and further being beneficial for the release of soil nutrients and for increasing crop yields. The correlation analysis results in this paper showed that the increase in SOC content was more favorable for increasing alkoxy $\mathrm{C}$ content and reducing the aromatic $\mathrm{C}$ content. The results also clarified (Table 1 ) the response of straw returning measures to the chemical structure of SOC. The organic C stabilization in soil is associated with their physical protection by soil microaggregates and oxyhydrates ${ }^{15}$, or with the recalcitrant matter protected by hydrophobic organic matter ${ }^{16}$, such as lignin and lipids ${ }^{12}$. Figure 1 showed that straw returning increased the contents of total SOC relative to CK treatment. Table 1 showed that straw returning increased the contents of aliphatic $\mathrm{C}$ compared with $\mathrm{CK}$ treatment. These data indicated that the selective immobilization and retention of aliphatic molecules such as hydroxyl acids, fatty acids and alkanes leads to the accumulation of $\mathrm{SOC}^{17,18}$.

\section{Conclusions}

The full straw returning combined with rotary tillage significantly increased the content of soil organic carbon compared with the modes of reduced rate of straw returning and full straw mulching. Compared with the treatment of stubble remaining in soil, the long-term straw returning treatments increased the contents of alkyl C and alkoxy $\mathrm{C}$ of soil organic carbon functional groups, and decreased the contents of aromatic $\mathrm{C}$ and carboxyl $\mathrm{C}$, which were consistent with the chemical shifts of the absorption peak of SOC functional groups in straw returning treatments. All the results indicated that after straw returning to the field, the content of refractory carbon in the soil decreased, the content of easily decomposed carbon increased, and the molecular structure was simplified.

\section{Methods}

Experimental design. This experiment was conducted at the Science and Technology experimental site $\left(125^{\circ} 27^{\prime} 5^{\prime \prime} \mathrm{N}, 49^{\circ} 33^{\prime} 35^{\prime \prime} \mathrm{E}\right)$ of the North Corporation of Sinograin, Nenjiang, Heilongjiang, China. The soil in the tested area was classified as Black soil according to Chinese Soil Taxonomy (as Mollisol according to USDA classification system) with a thick humus layer and clay texture. The area has a mid-temperate continental monsoon climate with an average annual temperature of -1.4 to $0.8^{\circ} \mathrm{C}$, precipitation of $450 \mathrm{~mm}$, a frost-free period of 115 days, and an effective accumulated temperature of $2150^{\circ} \mathrm{C}$. The basic physicochemical properties at $0-20 \mathrm{~cm}$ plow layer of soil were shown in Table 2 . The experiment included two modes: maize straw mulching (FG) and straw returning combined with rotary tillage. In the test plot, there were six 10-m ridges per treatment, and each treatment area was $39 \mathrm{~m}^{2}$. Each treatment has three replicate. The experiment started in 2012 under the continuous planting of maize, and the straw was mechanically crushed and returned to the field in the fall. In accordance with the adjustment in the $\mathrm{C} / \mathrm{N}$ of the straw, the amount of applied fertilizer was $\mathrm{N} 150 \mathrm{~kg} \mathrm{hm}^{-2}$, $\mathrm{P}_{2} \mathrm{O}_{5} 75 \mathrm{~kg} \mathrm{hm}^{-2}$, and $\mathrm{K}_{2} \mathrm{O} 75 \mathrm{~kg} \mathrm{hm}^{-2}$. Five treatments were included: (1) stubble remaining in the field, which served as the control (CK); (2) full straw mulching (FG); (3) full straw returning combined with rotary tillage (1 $\mathrm{XG})$; (4) $1 / 3$ of full straw returning combined with rotary tillage (1/3 XG); and (5) half of full straw returning combined with rotary tillage (1/2 XG).

Sample collection. Soil samples were collected after the maize (Demeiya 2) was harvested in November 2019. Five soil cores (diameter $5 \mathrm{~cm}$ ) were randomly taken from 0 to $20 \mathrm{~cm}$ depth in each plot, mixed thoroughly, and packed into cloth bags. After the crop roots and other debris were removed, the samples were air-dried for analyzing the content and chemical structure of SOC. 


\begin{tabular}{|l|c|}
\hline Item & Value \\
\hline Organic matter $\left(\mathrm{g} \mathrm{kg}^{-1}\right)$ & 45.9 \\
\hline Total $\mathrm{N}\left(\mathrm{g} \mathrm{kg}^{-1}\right)$ & 2.5 \\
\hline Total $\mathrm{P}\left(\mathrm{g} \mathrm{kg}^{-1}\right)$ & 2.0 \\
\hline Total $\mathrm{K}\left(\mathrm{g} \mathrm{kg}^{-1}\right)$ & 22.7 \\
\hline Available N $\left(\mathrm{mg} \mathrm{kg}^{-1}\right)$ & 211.9 \\
\hline Available $\mathrm{P}\left(\mathrm{mg} \mathrm{kg}^{-1}\right)$ & 78.6 \\
\hline Available $\mathrm{K}\left(\mathrm{mg} \mathrm{kg}^{-1}\right)$ & 226.7 \\
\hline Clay content $\left(<0.002 \mathrm{~mm}, \mathrm{~g} \mathrm{~kg}^{-1}\right)$ & 156.6 \\
\hline Silt content $\left(0.002 \sim 0.02 \mathrm{~mm}, \mathrm{~g} \mathrm{~kg}^{-1}\right)$ & 657.7 \\
\hline Sand content $\left(>0.02 \mathrm{~mm}, \mathrm{~g} \mathrm{~kg}^{-1}\right)$ & 185.7 \\
\hline
\end{tabular}

Table 2. Basic physicochemical properties of surface soil.

\begin{tabular}{|l|l|l|l|}
\hline Chemical shift & Functional groups of organic matter & Macro-molecular compounds \\
\hline \multirow{2}{*}{$0-45$} & \multirow{2}{*}{ Nonpolar alkyl C } & $\mathrm{CH}_{3}$ & \multirow{2}{*}{ Long chain, aliphatic, waxes, cutin, suberin } \\
\cline { 4 - 4 } & & $\left(\mathrm{CH}_{2}\right) \mathrm{n} / \mathrm{C} \& \mathrm{CH}$ & \\
\hline $45-60$ & \multirow{3}{*}{ O-Alkyl C } & Methoxyl C & N-Alkyl, amino acids, lignin \\
\cline { 4 - 4 } & & Carbonhydrate & Alcohols, amino sugars, tariric acid, dehydromatricaria ester, polyynes \\
\cline { 4 - 4 } $60-93$ & \multirow{2}{*}{ Aromatic C } & Aryl C & Hemicelluloses, cellulose, \\
\hline A3-110 & Phenolic & Tannin, lignin \\
\hline $110-142$ & \multirow{2}{*}{ Carbonyl C } & Carboxy C, Amide C & Amide, ester \\
\hline $142-160$ & Carbonyl C & Ketone, quinine, aldehyde \\
\hline $160-190$ & &
\end{tabular}

Table 3. ${ }^{13} \mathrm{C}$ solid-state NMR determination of organic carbon functional groups and corresponding highmolecular-weight compounds.

Determination of total soil organic carbon. The content of total SOC was measured using a TOC (total organic carbon) analyzer (NC2100, Jena, Germany,) after air-dried soil samples were passed through a 100-mesh sieve.

Purification of soil organic carbon. Five grams of air-dried soil was added to a $100 \mathrm{~mL}$ plastic centrifuge tube, followed by the addition of $50 \mathrm{~mL}$ of hydrogen fluoride (HF) solution $(10 \% \mathrm{v} / \mathrm{v})$. After the tube was capped, the solution was shaken for $1 \mathrm{~h}$ and centrifuged for $10 \mathrm{~min}\left(3000 \mathrm{r} \mathrm{min}^{-1}\right)$, and the supernatant was removed. Subsequently, the residue in the tube was treated with HF solution and then followed the above shaking and centrifuging steps. A total of eight repeats (according to the conditions of the actual samples) were performed with different duration of shaking $(4 \times 1 \mathrm{~h}, 3 \times 12 \mathrm{~h}$, and $1 \times 24 \mathrm{~h})$. Lastly, the residue in the tube was washed with double-distilled water four times, mainly to remove the residual HF in the soil sample. The detailed steps were as follows: $50 \mathrm{~mL}$ of double-distilled water was added into tube, shaken for $10 \mathrm{~min}$ and centrifuged $\left(3000 \mathrm{r} \mathrm{min}^{-1}\right)$ for $10 \mathrm{~min}$, and then the supernatant was removed. The purified samples with free-HF were dried in an oven at $40{ }^{\circ} \mathrm{C}$, ground through a 60 -mesh sieve, and stored in a Zip-lock bag for NMR measurement.

Determination of the chemical structure of soil organic carbon. The ${ }^{13} \mathrm{C}$ solid-state NMR spectrum was collected on a Bruker AV400 NMR spectrometer (Switzerland). The cross-polarization magic-angle spinning (CPMAS) technique was used, the ${ }^{13} \mathrm{C}$ NMR frequency was $400.18 \mathrm{MHz}$, the magic angle spinning frequency was $8 \mathrm{kHz}$, the contact time was $2 \mathrm{~ms}$, the delay time was $3 \mathrm{~s}$, and the number of data points was 3000. The chemical shift was calibrated based on the external standard sodium 2, 2-dimethyl-2-silapentane5 -sulfonate (DSS), the integrated area was automatically given by the instrument, and the relative content of organic C in each functional group of SOC was expressed as the percentage of the integrated area of a chemical shift interval to the total integrated area. The $\mathrm{C}$ structures corresponding to the chemical shift of the main ${ }^{13} \mathrm{C}$ signal of SOC (Table 3) were as follows: alkyl C region (0-45 ppm), alkoxy C region (45-110 ppm), aromatic C region (110-160 ppm), and carbonyl C region $(160-220 \mathrm{ppm})^{4,19}$.

Data analysis. NMR spectra (CPMAS $\left.{ }^{13} \mathrm{C}-\mathrm{NMR}\right)$ were analyzed using MestReNova professional software. After analyzing and extracting the source data, Microsoft Office Excel 2010 and Origin 8.0 software were used for data processing and plotting. The data in the "Available Data" were plotted using Origin by overlapping the fitted curve, and SPSS 17.0 (SPSS Inc., Chicago, USA) statistical analysis software was used to test for significant differences (Duncan's method) and for correlation analysis. 
Received: 28 July 2020; Accepted: 3 February 2021

Published online: 22 March 2021

\title{
References
}

1. Li, N., Sheng, M., You, M. \& Han, X. Advancement in research on application of ${ }^{13} \mathrm{C}$ NMR techniques to exploration of chemical structure of soil organic matter. Acta Pedol. Sin. 56(04), 796-812 (2019).

2. Guggenberger, G. et al. Land use effects on the composition of organic matter inparticle size separates of soil. II. CPMAS and solution 13C NMR analysis. Eur. J. Soil Sci. 46, 147-158 (1995).

3. Clemente, J. S. et al. Comparison of soil organic matter composition after incubation with maize leaves, roots, and stems. Geoderma 192, 86-96 (2013).

4. Mao, J. D. et al. Influence of animal manure application on the chemical structures of soil organic matter as investigated by advanced solid-state NMR and FTIR spectroscopy. Geoderma 146, 353-362 (2008).

5. Lal, R. Carbon management in agricultural soils. Mitigat. Adapt. Strategies Glob. Ghange 12, 303-322 (2007).

6. Schmmidt, M. W. I. et al. Persis-tence of soil organic matter as an ecosystem property. Nature 478, 49-56 (2011).

7. Lehmann, J. \& Kleber, M. The contentious nature of soil organic matter. Nature 528, 60-68 (2015).

8. Zhang, J. et al. Impact of the molecular structure of humic acid in black soil on the content of organic carbon in soil aggregates. Sci. Rep. 9, 11908 (2019).

9. Kögel-Knabner, I. The macromolecular organic composition of plant and microbial residues as inputs to soil organic matter. Soil Biol. Biochem. 34, 139-162 (2002).

10. Zhuo, S. N. \& Wen, Q. X. New advances in applying Nuclear Magnetic Resonance Spectroscopy in soil organic matter (In Chinese). Progress Soil Sci. 22(5), 46-52 (1994).

11. Feng, X. et al. Increased cuticular carbon sequestration and lignin oxidation in response to soil warming. Nat. Geosci. 1, 836-839 (2008).

12. von Lützow, M. et al. Stabilization of organic matter in temperate soils: mechanisms and their relevance under different soil conditions-a review. Eur. J. Soil Sci. 57, 426-445 (2006).

13. Mathers, N. J. \& Xu, Z. Solid-state ${ }^{13} \mathrm{C}$ NMR spectroscopy: characterization of soil organic matter under two contrasting residue management regimes in a 2-year-old pine plantation of subtropical Australia. Geoderma 114, 19-31 (2003).

14. Mahieu, N., Powlson, D. S. \& Randall, E. W. Statistical analysis of published carbon- ${ }^{13}$ CPMAS NMR spectra of soil organic matter. Soil Sci. Soc. Am. J. 63, 307-319 (1999).

15. Zhou, P., Song, G. H., Pa, G. X., Li, L. Q. \& Zhang, X. H. Role of chemical protection by binding to oxyhydrates in SOC sequestration in three typical paddy soils under long-term agro-ecosystem experiments from South China. Geoderma 153, 52-60 (2009).

16. Zhou, P., Pan, G. X., Spaccini, R. \& Piccolo, A. Molecular changes in particulate organic matter (POM) in a typical Chinese paddy soil under different long-termfertilizer treatments. Eur. J. Soil Sci. 61, 231-242 (2010).

17. De Marco, A. et al. Decomposition of black locust and black pine leaf litter in two coeval forest stands on Mount Vesuvius and dynamics of organic components assessed through proximate analysis and NMR spectroscopy. Soil Biol. Biochem. 51, 1-15 (2012).

18. Jandl, G., Baum, C., Blumschein, A. \& Leinweber, P. The impact of short rotation coppice on the concentrations of aliphatic soil lipids. Plant Soil 350, 163-177 (2012).

19. Li, C. M., Wang, X. Y. \& Sun, B. Advances in studying mechanisms of plant residue decomposition and turnover based on solidstate ${ }^{13} \mathrm{C}$ nuclear magnetic resonance spectroscopy. Soils 49(4), 658-664 (2017).

\section{Acknowledgements}

The study was supported by the National Key R\&D Program of China (2018YFD0200407, 2016YFD0300806), National Natural Science Foundation of China (41771284), and the Development and Cooperation Program of Green Agriculture of Heihe City (KJTG-2019-02HH-03). Agricultural Science and Technology Innovation Leap Project (HNK2019CX13).

\section{Author contributions}

J.Z. and D.W. conceived the project. S.Z., F.C., B.Z. designed the experiment, E.K., Y.J., G.M. and Y.C. performed the filed sampling and lab analyses, J.Z., and S.Z. carried out the data analysis, J.Z. wrote the first draft, and S.Z. revised and comments on the manuscript. All co-authors approved the manuscript.

\section{Competing interests}

The authors declare no competing interests.

\section{Additional information}

Correspondence and requests for materials should be addressed to D.W.

Reprints and permissions information is available at www.nature.com/reprints.

Publisher's note Springer Nature remains neutral with regard to jurisdictional claims in published maps and institutional affiliations.

\begin{abstract}
(c) (i) Open Access This article is licensed under a Creative Commons Attribution 4.0 International cc) License, which permits use, sharing, adaptation, distribution and reproduction in any medium or format, as long as you give appropriate credit to the original author(s) and the source, provide a link to the Creative Commons licence, and indicate if changes were made. The images or other third party material in this article are included in the article's Creative Commons licence, unless indicated otherwise in a credit line to the material. If material is not included in the article's Creative Commons licence and your intended use is not permitted by statutory regulation or exceeds the permitted use, you will need to obtain permission directly from the copyright holder. To view a copy of this licence, visit http://creativecommons.org/licenses/by/4.0/.
\end{abstract}

(c) The Author(s) 2021 